\title{
Making a place for bibliotherapy on the shelves of a curriculum materials center: The case for helping pre-service teachers use developmental bibliotherapy in the classroom By Amy Catalano
}

\begin{abstract}
:
With developmental bibliotherapy frequently used in schools, this article addresses the necessity of educating future teachers in the proper implementation of bibliotherapy so that their students may reap the benefits and avoid inadvertent harm. The purpose of this article is to discuss the benefits and use of developmental bibliotherapy in the classroom and to promote the same. The article also reviews the role of the education librarian in a Curriculum Materials Center (CMC).
\end{abstract}

\section{Introduction}

The purpose of a Curriculum Materials Center (CMC) is to provide materials to pre-service or in-service teachers, (i.e., Student teachers or teachers in the beginning of their teacher education) in order for them to create lesson plans as well as to allow them to become familiar with the many materials available for use in education. Many CMCs include not only textbooks, activity books and manipulatives, but also children's literature and psycho/socio-educational games (the latter of which is geared to be used by counselors in training). Bibliotherapy's genesis and prescription historically began with licensed therapists and physicians. It falls under two different categories: Therapists practice clinical bibliotherapy while librarians and/or teachers may practice Developmental Bibliotherapy (DB). With the use of DB prevalent in schools, it is necessary to educate future teachers in the proper implementation of bibliotherapy so that students may reap the benefits and avoid inadvertent harm. The purpose of this article is to discuss the benefits and use of DB in the classroom and to promote the same. The article also reviews the role of the education librarian in a Curriculum Materials Center (CMC).

\section{History and Perceptions of Developmental Bibliotherapy}

The roots of bibliotherapy began in the nineteenth century when doctors started "prescribing" books (with the aid of the librarian) in the $19^{\text {th }}$ century, to patients in a hospital so that they may become familiar with the symptoms of their medical issues (Warner 1980). Bibliotherapy has since evolved as a technique used by mental health professionals to help guide clients through their problems by directed reading. This is called Clinical Bibliotherapy with the books being used to stimulate discussion of difficult feelings "or facilitate resolution of more significant behavioral and emotional issues" (Mcmillen 2006). Developmental Bibliotherapy however, can be used in the classroom where the goal may be to facilitate normal development or to educate students about attitudes, feelings and behaviors such as bullying, divorce, and self-image (Mcmillen 2006). DB can also be defined as a "process of dynamic interaction between an individual and literature through facilitated dialogue...[where] bibliotherapy underscores the importance of the reader's feeling response to the literature.” (Schlicter \& Burke 1994). The research strongly suggests that for DB to be effective discussion must occur. Various methods by which to facilitate appropriate discussion will be $\sim$ Herbert et al. (2001) addressed.

\section{Controversy}

In public libraries for both children and adults, reference librarians practice bibliotherapy directly with their patrons. A parent, for example, may come to a children's librarian to request a book about death to read to a child who has just lost a grandparent, and the librarian may consult a ready-made bibliography or search the catalog using the subject headings "grief and children" for resources. A librarian knowledgeable of some facets of bibliotherapy may provide a parent with several choices of books while offering a synopsis of each during the reference interview so that the best age, and situation-appropriate, books may be chosen. This particular brand of bibliotherapy is not Developmental Bibliotherapy and is often considered controversial as it appears to be a watered-down and non-professional attempt at Clinical Bibliotherapy. However, if a parent is requesting a title for their own child and reads the work first then the responsibility lies within the parent to make appropriate decisions with the guidance of the librarian. If the librarian is doing his or her job in ensuring that the content of the 
book does not include any inappropriate language or themes that a parent or child may find offensive, then harm is usually avoided. "Concern kicks in when giving someone a book who has mental health issues morphs into therapy" (Jones 2006). Controversy may also follow if books are selected that may have strong sexual or religious themes. Avoiding controversy will be addressed $n$ the applications section of this article.

In an academic library, the education librarian has the benefit of being in the role of teacher and thus can use this role to instruct their patrons and students. In the CMC the librarian would not directly practice Developmental Bibliotherapy with their patrons (who are students of education) but would guide them through the appropriate methods of implementing DB in their classrooms. Many professionals argue that the term "supportive knowledge" should be used instead of bibliotherapy (Baruchson-Arbib 2000).

\section{Uses of Developmental Bibliotherapy}

The prevalence of trauma, and the direct affect it has on a child's ability to learn, forces us to look at ways we can help our young students beyond that of sessions with a psychologist in or out of school. This is of particular interest because these issues were typically not addressed in years past. In addition to students who suffer some type of loss through death or change in family dynamic, there are those whose parents may be deployed in the military during peace and wartime. There are also issues of bullying, drug use, sexual abuse, neglect, homelessness, school anxiety, negative body image, and sexual orientation. Using DB with the entire class allows for those students to empathize with those who suffer anxieties created by childhood traumas. Students can also develop problem-solving skills whether or they have experienced these traumas themselves.

DB need not only be used with children who are suffering in some manner, but also used in classrooms as a preventative measure. Teachers can address common problems among schoolchildren to aid in awareness, and to facilitate critical thinking and problem solving skills. As Knoth (2006) expresses "I would rather inoculate children than treat the symptoms of the emotional trauma. We give children vaccinations against measles. We can't vaccinate against divorce, but we can give children some emotional knowledge to use when their families do go through a divorce.” In an article on Math Anxiety, Herbert (1997) says that the role of the teacher is to prevent problems not cure them. Prater, et al. (2006) states that schools typically intervene with prevention, early intervention, or treatment programs and that "Bibliotherapy is one technique that can be used at all three levels.”

In reference to addressing homosexuality in schools, Vare and Norton (2004) believe that "because schools reflect the homophobic attitudes of today's society, they often devalue the sexual orientation of gay and lesbian teens in their curriculum, extracurricular activities and student services." While Vare and Norton make a blanket statement about schools and homosexuality, it is also true that homosexual students may often feel isolated and are at risk for abuse. Vare and Norton also assert that when schools fail to "acknowledge the existence of homosexual youth [it can] be devastating to these adolescents... [the school's] current silence sends an alienating message of denial and despair to gay and lesbian youths." School systems hold the responsibility to educate their students to be tolerant of all people. Through bibliotherapy, not only can students be educated and thus encouraged to empathize with homosexual students, but also gay or lesbian students have a greater awareness of the resources available to them. The principles that apply to homosexual youths also apply to students who suffer from any type of anxiety. Through time-tested processes of the implementation of DB, students can come away from the experience with knowledge of themselves and those like them, as well as an empathy for others who are experiencing pain of a different nature.

\section{Processes for the Implementation of DB}

The following processes of implementation are used in both Developmental and Clinical Bibliotherapy. These processes are the foundations of bibliotherapy and describe how it works to help people, in this case children, through their problems. While some of the following examples indicate a clinical use of bibliotherapy, they are used in this article solely to illustrate how the process works.

Nearly all proponents of DB describe three stages that include Identification, Catharsis and Insight (Morawski 1997, Kramer \& Smith 2005). Identification is the process of affiliating some real or fictional character with oneself. To facilitate this step "students should be encouraged to recall relevant incidents from their own lives." (Morawski 1997). This step also encourages children to recognize that they are not alone in their situation...that their situation is normal (Kramer \& Smith 2005). 
Catharsis is the process of the release of tension. DB "may strike at a deep emotional level [when students are reading] books written by compassionate people who have made some progress in their own painful struggle to know themselves... as the character works through a problem and releases emotional tension identification becomes further established" (Morawski, 1997).

Insight is the point at which readers develop knowledge about themselves and the world and the use of activities such as discussion, is essential to allow this last stage to occur. It is the interaction with the teacher that allows for insight into how a problem is met or solved. Herbert (1997) describes a fourth stage he coins "universalization...that we are not all in this alone" but most professionals (Kramer \& Smith 2005, Morawski 1997) deem that term synonymous with identification.

In the case of grieving children, Manifold (2007) discusses the correlation between the aesthetics of a picture book and that of "emotionally painful experiences." They are related as "unfolding in a sequenced order...trigger[ing] a powerful emotional response, which compels [one to ask]: 'What does this mean?' 'Why did this happen?' and 'What do I do now?"' If one can make sense of the "triggering” event then one may eventually arrive at a "resolution of being qualitatively different than that before the experience." In this process it is not only the identification and cathartic aspects of the DB process that enable a child to heal, it is the rhythm and soothing of the art of the written word and illustrations, and to the imagination that has been ignited by that art. In part, children can create psychological safe spaces by way of this process. Manifold (2007) contends that art images "draw on feelings, abstract memories, and metaphoric associations whereas narratives spark the reader's imagination to weave explanation and meaning. Images with narratives become tools of imaginative thinking in guiding young readers through and out of sorrow."

Prater et al. (2006) discusses a ten-step model for implementing Bibliotherapy. Although it is important to note that their process seeks to address, and further prevent problems already occurring, not prevent them in the way DB seeks to. Yet the model still incorporates the processes necessary for $\mathrm{DB}$ to be effective: identity, catharsis and insight. Their model includes these steps:

- Develop rapport, trust, and confidence with the student.

- Identify other school personnel who may assist.
- Solicit support from the student's parents or guardians.

- Define a specific problem the student is experiencing.

- Create goals and activities to address the problem.

- Research and select books appropriate for the situation.

- Introduce the book to the student.

- Incorporate reading activities.

- Implement post-reading activities.

- Evaluate the effects of bibliotherapy on the student.

In this process the steps of identify, catharsis and insight are addressed while incorporating additional steps to help guide the teacher/therapist by providing more specific suggestions for implementation.

\section{The Case for Developmental Bibliotherapy}

Although empirical research is necessary to verify the effectiveness of bibliotherapy, particularly with elementary school children, many professionals advocate the use of DB, particularly as a means for teaching problem solving (Forgan 2002), decreasing fears (Pearson 2003), supporting gay and lesbian students (Vare and Norton 2004), overcoming math anxiety (Herbert 1997), and supporting students dealing with death (Corr 2004) and divorce (Kramer and Smith 1998). The following paragraphs go into more detail on how DB can assist with the issues that surround Special Education, Gifted and Talented, grieving and sexual abuse.

Bibliotherapy, specifically biography, is also "a good source for those children who are communicatively impaired. They can learn about significant contributions that have been made by similarly impaired persons" such as Helen Keller (Hendrickson 1988). In their article on using biography to counsel gifted young women, Herbert, Long and Neumeister (2001) offer a different purpose for the use of biography. Gifted teenage girls often face emotional issues not met by other girls their age. There are high expectations for them by their parents, but their friends and sometimes their teachers, expect them to perform like their peers. Herbert, et al. (2001) expresses that in reading biographies the reader may meet personalities that they themselves would like to emulate. "Reading about noble deeds may not of itself produce noble character, but such reading is undoubtedly a source of inspiration. The ambitious young person who is fond of reading finds enchantment in the lives of people who overcame obstacles to achievement though dint of hard effort.” 
Children who are grieving, either because of the death of a loved one, divorce, or other loss, are profoundly inhibited from learning because they lack the ability to focus and retain information (Manifold 2007). Manifold (2007) goes on to state that because "visual and audible rhythms and sensitively constructed narratives have been found to have calming therapeutic affects on emotional suffering, picture books may be particularly helpful resources for reassuring emotionally distressed children and redirecting their attentions back to classroom instruction.”

McDaniel (2001) discusses using children's literature in the prevention of sexual abuse. In addition to employing the concept of identification as a cause for teaching abused children that they are not "the only one," she also addresses the perception of many parents that abuse will "not happen to their children." She states that "We can break the cycle of child sexual abuse by creating an environment in which taboo subjects can be discussed openly and accurate information is readily available." Prevention is much easier than dealing with the physical damage and pain that comes with sexual abuse. McDaniel suggests, for example, "It may be worthwhile to reevaluate the way in which we teach our children to unquestionably obey authority figures...the sex offender takes full advantage of this teaching of obedience to all adults." Unfortunately, this type of bibliotherapy puts the responsibility of prevention on the child. Thus it is essential that adults effectively educate their children as to how to prevent sexual abuse.

\section{Limitations and Cautions in Usage}

Much of the controversy surrounding non-clinicians (i.e., librarians and teachers) executing bibliotherapy is that there is fear that more harm than good - however well intended - will be done. That being said, no formal training is necessary for an adult or child to read a book, nor is formal training necessary to discuss that book. Therefore, with proper education on the use of DB, knowledge of child development, and careful astute book selection, educators may confidently implement DB with their students. Manifold (2007) states "Sorrow that is properly addressed can resolve in learning" so why should this learning not take place under the hand of a well- trained and sensitive teacher?
However, books should not be expected to carry too heavy a burden. A book cannot be expected to stand alone as a healing tool without forethought, research, planning, reading the book ahead of time and anticipating questions. Warner (1980) discusses research from in a clinical trial where schoolchildren's anxieties were actually heightened after a course of bibliotherapy. The researcher himself expressed that it is likely that discussion after reading the "prescribed" books was neither sufficient nor calming. For the discussion to be effective, it must include a conversation about solutions to the problem. One way to implement this aspect of DB is to have students role play through variations of solutions.

Sometimes neither the book nor the method, no matter how well researched and implemented, can help the child. Sometimes the limitation lies in the personality of the participant. Kramer and Smith (1998) state that a "participant may have a bias that can affect his/her perception of the story. This bias may prohibit some children from identifying with certain story characters. However, the use of followup activities may help negate the effects of bias." The limitation may also lie in the facilitator, in this case the teacher. A teacher who does not have a good understanding of children or the subject matter may be ineffective at interacting with children in this manner. Kramer and Smith (1997) offer the example of children of divorce in implementing bibliotherapy techniques for children. They state that it is important to be aware of children's typical reactions to divorce during the early childhood years.

\section{Role of Librarian and Teacher}

Primarily, the role of education librarians is to be familiar with the literature in their Curriculum Materials Center (CMC) or library. Secondly, if librarians are to guide (pre-service) teachers in the use of literature or non-fiction they must be familiar, by way of research, of the suggested works by professional therapists for specific issues such as divorce, grief, anxiety, bullying etc. Lastly as an academic education librarian, they should be familiar in the procedures of implementing Developmental Bibliography. "Concern kicks in when giving someone a book who has mental health issues morphs into therapy" (Jones 2006). There are appropriate roles for librarians in DB such as collaborating with a mental health specialist to provide subject appropriate books 
as well as specific passages from those books. The education librarian should always remain apprised of current issues in schools and in the media.

Warner asks "Who is the therapist: the book or the person directing the reading?" This question illustrates the issue at hand; that bibliotherapy, whether clinical or developmental, is not about doing a subject search in a library database, compiling a bibliography on a therapy issue, and then handing over a book. DB involves education of the issues, age appropriate titles and the proper methods for engaging students in a discussion conducive to facilitating problem solving and coping skills. It also calls for the sensitivity to recognize when or whether or not an issue should be discussed at all. Warner (1980) asserts that some educators inappropriately may present moral and value education, i.e., teaching children to behave as we would like them to, under the aegis of Developmental Bibliography.

When making selections, Manifold (2007) suggests that parents, teachers and librarians should look carefully at the conclusions of picture books that the author and illustrator provide. "If picture books are to elicit the calming and healing effects of imagination, it is important that the answer proposed by the author and illustrator treat the universal question with dignity, take an ecumenical approach to the answer, and avoid presenting the answer as an absolute certainty, thereby allowing room for a reader's imaginative interpretation." Manifold goes on to suggest that such therapeutic books should be made available to all students as reading choices so that any sorrowful or otherwise anxious child may "explore painful topics in a private way.”

\section{Librarian's Role and Applications for the Curriculum Materials Center}

The librarian's role in effectively implementing DB is manyfold. Their role includes collection development, research of the topic, outreach to faculty and students and providing access to information about DB. The librarian should be aware of issues in schools and the community that are likely to be addressed by teachers. A librarian whose goal is to help students does not avoid those topics that are controversial or uncomfortable to address, such as teen sexuality. Librarians can stay current on these issues by keeping in contact with school counselors in local districts. In addition to collecting quality materials in not only children's and adolescent literature, the Curriculum Materials Center librarian will also want to procure material on bibliotherapy itself and non-fiction books about the issues. In order to support developmental bibliotherapy in the CMC the librarian should first develop a collection that includes materials on a variety of issues for different age groups. Many of the articles referenced here include a bibliography of books as well as suggested activities. Books such as Books You Kids Will Talk About! by Hepler and Salvadore, Books to help children cope with separation and loss by Rudman, Gagne and Bernstein, and Sensitive Issues: An Annotated Guide to Children's Literature $K-6$ by Rasinski and Gillespie are good resources for quality bibliotherapeutic materials.

It is the librarian's job to evaluate popular literature for developmental appropriateness, content and accuracy, as well as evaluate the authority of a work. Librarians often partner with mental health professionals and faculty from the counseling program at their school where the health professional provide criteria and themes, and the librarian provides titles and passages of books. Librarians are the source of knowledge on both fiction and non-fiction and as such can alert other professionals to literature that contains inappropriate language or problematic issues such as racism or sexism. Finally, both the librarian and the pre/inservice-teacher will want to create up-to-date bibliographies on bibliotherapeutic issues for quick reference.

Librarians, in their unique role as teachers and providers of information, are the front line on methods and research for implementing bibliotherapy. They should be aware of the necessity for discussion in classroom after reading children's literature about an issue and be sure to share these processes with their patrons.

While librarians in a college or university setting may have the authority, right and interest to promote freedom of information to their patrons, the teachers in elementary and secondary schools do not. Teachers are in loco parentis, meaning that they are in the role of parent when schoolchildren are in their care. As such they must make their literature selections carefully. Because educators want to avoid creating any anxiety in children (and their parents). It is very possible that a book recommended, for example, to a Gay, Lesbian, Bisexual, or Transgendered (GLBT) adolescent could be a work that is challenged within the community. When working with elementary school children in particular, a teacher will want to choose their themes carefully. They may want to avoid topics that may be very personal to a child such as divorce or war. Topics such as bullying, safety, stranger danger and character 
education are subjects which are most often discussed in school with little controversy.

In order to educate teachers in the proper implementation of DB, education librarians often reach out to the teaching faculty of their institutions to initiate workshops or seminars on the topic. They can also discuss the subject briefly during bibliographic instruction in the appropriate classes. In these classes students will not only be provided with information about DB but also with bibliographies of select material and discussion activities.

\section{Conclusions}

It would be careless to suggest that following the above guidelines would be a safe and sufficient way to implement developmental bibliotherapy for children without a further note of caution. Teachers are trained in not only the creation and use of curriculum in the classroom but in the developmental milestones of their young charges. It is essential that teachers use this knowledge along with their teaching skills to carefully address sensitive topics with their students. Research of the topic and critical thinking skills are essential to the successful employment of DB. Librarians who work with teachers are in the unique position of being able to provide instruction and materials related to DB because they hold the dual position of educators as well as portals to information specifically in the realm of children's literature and methods of education.

\section{References:}

Baruchson-Arbib, Shifra. (2000). Bibliotherapy in school libraries: An Israeli experiment. School Libraries Worldwide, 6(2), 102-110.

Duimstra, L. (2003). Teasing and name-calling: Using books to help students cope. Teacher Librarian, 31(2), 8-11.

Forgan, J.W. (2002). Using bibliotherapy to teach problem solving. Intervention in School and Clinic, 38(2), 75-82.

Hendrickson, L.B. (1988). The 'right' book for the child in distress. School Library Journal, 40-4.

Herbert, T.P. \& Furner, J.M. (1997). Helping high ability students overcome math anxiety through bibliotherapy. Journal of secondary gifted education, 8(4), 164-78.

Herbert, T.P., Long, L.A. \& Neumeister, K.L. (2001). Using biography to counsel gifted young women. Journal of Secondary Gifted Education 12(2), 62-79.

Johnstun, M.L., Johnstun, M.R., Prater, M.A. \& Taylor Dyches, T. (2006). Using children's books as bibliotherapy for at-risk students: A guide for teachers. Preventing School Failure, 50(4), 5-13.

Jones, J.L. 92006). A closer look at bibliotherapy. Young Adult Library Services, 24-27.

Kramer, P.A. \& Smith, G.G. (1998). Easing the pain of divorce through children's literature. Early Childhood Education Journal, 26(2)
Manifold, M.C. (2007). The healing picture book: An aesthetic of sorrow. Teacher Librarian 34(3), 20-6.

McDaniel, C. (2001). Children's literature as prevention of child sexual abuse. Children's Literature in Education, 32(3), 203-224.

McMillen, P. (2006). A therapeutic collaboration: The bibliotherapy education project at Oregon State University.

Morawski, C.M. (1997). A role for bibliotherapy in teacher education. Reading Horizons, 37, 243-59.

Norton, T. L. \& Vare, J.W. (2004). Bibliotherapy for gay and lesbian youth: Overcoming the structure of silence. The Clearing House, 77(5), 190-4.

Pearson, Q.M. (2003). Helping children cope with fears: Using children's literature classroom guidance. Professional School Counseling 7 (10), 15-19

Schreur, G. (2006). Using bibliotherapy with suspended students. Reclaiming Children and Youth, 15(2), 106111.

Visser Knoth, M. (2006). What ails bibliotherapy. Horn Book Magazine, 273-276.

Warner, L. (1980). The myth of bibliotherapy. School Library Journal, 107-111

Wolpow. R \& Askov, E. (1998). Strong in broken places: literacy instruction for survivors of pervasive trauma. Journal of Adolescent and Adult Literacy, 42(1), 50-57.

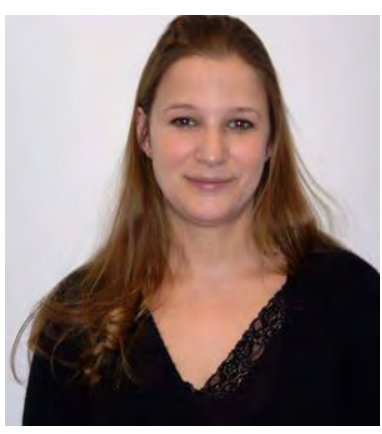

Amy Catalano (formerly Cianciulli) is Assistant Professor of Library Services and director of the Curriculum Materials Center at Hofstra University in Hempstead, NY. She was previously a high school social studies teacher and has been an academic librarian for two years. In her Curriculum Materials Center she is actively working to create Psycho-Educational Games and Clinical Bibliotherapy collections for use by Counseling Interns. In addition to children's literature, Catalano is interested in the promotion of mathematics, science and foreign language teaching. The Education Division of Special Libraries Association enhances her professional life by providing a link to the specialized information related to being an education librarian, such as websites, conferences and symposiums. Being on the Education Division's Discussion Group allows for education librarians to discuss issues specific to them. Some of her personal hobbies include studying and collecting works of rarely taught foreign languages such as Coptic. She and her children also collect children's pop-up books.

amy.cianciulli@hofstra.edu 